3. Gavier-Widén D, Ståhl K, Dixon L. No hasty solutions for African swine fever. Science. 2020;367:622-4. https://doi.org/10.1126/science.aaz8590

4. Chenais E, Ståhl K, Guberti V, Depner K. Identification of wild boar-habitat epidemiologic cycle in African swine fever epizootic. Emerg Infect Dis. 2018;24:810-2. https://doi.org/10.3201/eid2404.172127

5. Abrahantes JC, Gogin A, Richardson J, Gervelmeyer A, et al.; European Food Safety Authority. Epidemiological analyses on African swine fever in the Baltic countries and Poland. EFSA Journal. 2017;15:e04732. https://doi.org/10.2903/ j.efsa.2017.4732

6. Vergne T, Chen-Fu C, Li S, Cappelle J, Edwards J, Martin V, et al. Pig empire under infectious threat: risk of African swine fever introduction into the People's Republic of China. Vet Rec. 2017;181:117. https://doi.org/10.1136/vr.103950

7. Bosch J, Iglesias I, Muñoz MJ, de la Torre A. A cartographic tool for managing African swine fever in Eurasia: mapping wild boar distribution based on the quality of available habitats. Transbound Emerg Dis. 2017;64:1720-33. https://doi.org/10.1111/tbed.12559

8. Wu S, Chen H, Cai X. Preliminary study on the population structures and reproductive habit in wild boar (Sus scrofa) in Dawaling Natural Reserve. Acta Theriologica Sinica. 2000;20:151-6.

9. Śmietanka K, Woźniakowski G, Kozak E, Niemczuk K, Frączyk M, Bocian $€$, et al. African swine fever epidemic, Poland, 2014-2015. Emerg Infect Dis. 2016;22:1201-7. https://doi.org/10.3201/eid2207.151708

10. Liu Q, Yan K, Lu Y, Li M, Yan Y. Conflict between wild boars (Sus scrofa) and farmers: distribution, impacts, and suggestions for management of wild boars in the Three Gorges Reservoir Area. Journal of Mountain Science. 2019;16:2404-16. https://doi.org/10.1007/s11629-019-5453-4

Address for correspondence: Timothée Vergne, UMR ENVT-INRAE 1225, National Veterinary School of Toulouse, 23 chemin des Capelles, 31300 Toulouse, France; email: timothee.vergne@envt.fr

\section{Review of Mental Health Response to COVID-19, China}

\author{
Adriana Miu, Hui Cao, Bohan Zhang, ${ }^{1}$ Huaiyu Zhang \\ Author affiliations: University of Texas Southwestern Medical \\ Center, Dallas, Texas, USA (A. Miu); Beijing Institute of Education, \\ Beijing, China ( $\mathrm{H}$. Cao); Lesley University, Cambridge, Massachu- \\ setts, USA (B. Zhang); University of California San Francisco, San \\ Francisco, California, USA (H. Zhang)
}

DOI: https://doi.org/10.3201/eid2610.201113

${ }^{1}$ Current affiliation: Private practice, Nanjing, China.
Public mental health response to coronavirus disease is essential. After reviewing systemic and local efforts in China, we found efficient coordination and human resources. We recommend better symptom assessment, monitoring of organizations, and basic needs protection. This recommendation can inform how other countries can overcome mental health challenges during this pandemic.

$\mathrm{T}$ he coronavirus disease (COVID-19) outbreak and quarantines have caused major distress in China $(1,2)$. Therefore, effective public mental health response to COVID-19 is needed (3). We review systemic and local mental health efforts in China based on psychiatric emergency guidelines from the InterAgency Standing Committee (4). These guidelines are coordination between multiple sectors; human resources; assessment, monitoring, and evaluation; and protection and human rights standards. Our discussion will inform mental health response for the COVID-19 pandemic.

Mental health efforts in China have been coordinated and facilitated through multiple systems, including government, academic societies, universities, hospitals, and nonprofit organizations (5). Services include a countrywide $24 / 7$ hotline, text support through apps, psychoeducation materials, and webinars (5). The government prioritized psychosocial support for COVID-19, as shown by the National Health Commission mandate requiring all mental health associations to provide psychosocial support, establish professional focus groups, and aid the provincial and city health departments (6).

Academic organizations in psychology (Chinese Psychological Society [CPS]) (Table) and psychiatry (Chinese Society of Psychiatry) provide evidence-based guidelines on psychosocial support and training $(5,7)$. The Ministry of Education (MoE) has mandated all college counselors across the nation to volunteer for the primary Huazhong University hotline at the epicenter in Wuhan (8). At the systemic level, there is good coordination and resource allocation. The government agencies coordinate human resources, and academic associations provide professional knowledge and guidelines for frontline effort.

Coordination and resource allocation were compiled from local efforts at the Wuhan epicenter (Appendix, https://wwwnc.cdc.gov/EID/ article/26/10/20-1113-App1.pdf). On January 23, 2020, immediately after the quarantine, Zhongnan Hospital and the Hubei Psychological Consultant Association began offering hotline services. As of April 30 , more than 2,000 persons had been served. Beyond the hotline, Wuhan University and Huazhong 
Table. Case-patients with coronavirus disease in China and respective response from the Chinese Psychological Society

\begin{tabular}{|c|c|c|}
\hline Date & Coronavirus disease & Chinese Psychological Society response \\
\hline 2019 Dec 9 & First suspected case & None \\
\hline 2019 Dec 31 & Cluster of pneumonia cases in Wuhan & None \\
\hline 2020 Jan 20 & Cases in China, Thailand, Japan, and South Korea & None \\
\hline 2020 Jan 21 & Cases reported in other provinces & None \\
\hline 2020 Jan 23 & Lockdown of Wuhan & None \\
\hline 2020 Jan 25 & Cases in all of China except Tibet & None \\
\hline 2020 Jan 26 & No event & Published self-help article on emotional support \\
\hline 2020 Jan 27 & Lockdown of all cities in Hubei & None \\
\hline 2020 Jan 28 & No event & Conducted first round of training for supervisors \\
\hline 2020 Jan 29 & No event & Published list of psychologist consultants \\
\hline 2020 Jan 30 & $\begin{array}{l}\text { World Health Organization declared public health } \\
\text { emergency of international concern }\end{array}$ & None \\
\hline 2020 Jan 31 & No event & Published handbook for hotline organizations and volunteers \\
\hline 2020 Feb 2 & No event & Published list of organizations for hotline and counseling \\
\hline 2020 Feb 3 & No event & Updated guidelines for hotline organization \\
\hline 2020 Feb 5 & Foreign airlines cancelled flights to China & None \\
\hline 2020 Feb 6 & No event & Published ethics guidelines \\
\hline 2020 Feb 7 & Death of whistleblower doctor & None \\
\hline 2020 Feb 7 & No event & Published webinars for general public \\
\hline 2020 Feb 9 & No event & Published handbook on self-care for volunteers \\
\hline 2020 Feb 10 & No event & Conducted second round of training for supervisors \\
\hline 2020 Feb 13 & No event & Published hotline support questions and answers \\
\hline 2020 Mar 3 & No event & Updated handbook for hotline organizations and volunteers \\
\hline 2020 Mar 3 & No event & Published list of 52 recommended hotline organizations \\
\hline 2020 Mar 8 & No event & $\begin{array}{l}\text { Conducted 7-day self-help psychosocial support } \\
\text { for healthcare workers }\end{array}$ \\
\hline
\end{tabular}

University provide online text support through apps staffed by $>3,000$ professionals across China. This support demonstrates how hospitals, professional associations, and universities have collectively provided immediate resources. Furthermore, resources have been mobilized from other regions to support the epicenter. The hotline of Huazhong University became the primary hotline for Hubei residents and was staffed by college counselors throughout China under the mandate of the MoE (8). Psychologists and nurses from other provinces were dispatched to $\mathrm{Wu}$ han Third Hospital on January 28. Psychosocial efforts might be sourced by different organizations, but they illustrate pooling of resources and coordination from other regions to ensure access to psychosocial support at the epicenter.

The MoE and CPS recruited professionals and volunteers across China, which suggests adequate resource allocation $(5,7,8)$. CPS trained 1,448 registered psychologists in train-the-trainer workshops (8); these psychologists in turn supervised and provided live consultations to frontline volunteers (7). China has also implemented Artificial Intelligence Tree Holes Rescue to reduce suicidal risk. These programs demonstrate efficient task-sharing, by pooling professionals together, supervising less-trained staff, and using technology to overcome resource shortages.

The Inter-Agency Standing Committee calls for assessment of mental well-being and program evaluation of psychsocial support effectiveness (4). Guidelines of the National Health Commission document the need for assessment and program evaluation, but enforcement was unclear beyond the guidelines (6). Although there were nationwide surveys of psychological well-being $(9,10)$, they did not describe use of surveys in psychological services. Clinical assessment, such as previous mental illness history or stressors (e.g., grief, financial stress), should be routinely integrated into services.

CPS published a list of approved hotline organizations based on survey evaluation of organizations (8). However, this survey was not conducted until 3 weeks after the outbreak. At the outset of a psychiatric emergency, a team of professionals should evaluate and monitor whether individual organizations meet national guidelines. A negative experience from an unregulated organization can deter persons from seeking help.

Although COVID-19 does not cause intentional harm, there are human rights issues on access to basic needs (4). During the sudden lockdown of $\mathrm{Wu}-$ han, access to food and medical needs was threatened because of food hoarding, price gouging, and transportation freeze. In response, the government coordinated supply with tons of vegetables and meat. These threats were documented by nationwide surveys of well-being of persons. Professionals can further use these documentations to advocate for victims. For example, professionals can educate policymakers about the need for transparency, such 
as informing the public about food shortage while reassuring the public that supply will arrive in a few days. China has provided free, country-wide psychosocial support, funded by the government and institutions (5-7). The accessibility is remarkable compared with that in other countries that depend on health insurance benefits.

Our review suggests that China has overcome resource shortages with coordination and resource allocation in its mental health response. The government, universities, and academic societies provide coordination, and independent organizations provide local support. We recommend integration of assessment in direct support, monitoring of organizations, and advocating for affected persons. These recommendations can inform how other countries can overcome shortage of mental health resources when facing this pandemic.

\section{About the Author}

Dr. Miu is an assistant professor and a licensed clinical psychologist in the Department of Psychiatry at the University of Texas, Southwestern Medical Center, Dallas, TX. Her research interests include social-cognitive factors, such as growth mindset and hostile attribution bias.

\section{References}

1. Brooks SK, Webster RK, Smith LE, Woodland L, Wessely S, Greenberg N, et al. The psychological impact of quarantine and how to reduce it: rapid review of the evidence. Lancet. 2020;395:912-20. https://doi.org/10.1016/ S0140-6736(20)30460-8

2. Gao J, Zheng P, Jia Y, Chen H, Mao Y, Chen S, et al. Mental health problems and social media exposure during COVID-19 outbreak. PLoS One. 2020;15:e0231924. https://doi.org/10.1371/journal.pone.0231924

3. Dong L, Bouey J. Public mental health crisis during COVID-19 pandemic, China. Emerg Infect Dis. 2020;26:16168. https://doi.org/10.3201/eid2607.202407

4. Inter-Agency Standing Committee. IASC guidelines on mental health and psychosocial support in emergency settings. Geneva: The Committee; 2007.

5. Li W, Yang Y, Liu ZH, Zhao YJ, Zhang Q, Zhang L, et al. Progression of mental health services during the COVID-19 outbreak in China. Int J Biol Sci. 2020;16:1732-8. https://doi.org/10.7150/ijbs.45120

6. National Health Commission of China. Principles of the emergency psychological crisis interventions for the new coronavirus pneumonia, January 26, 2020 [in Chinese] [cited 2020 Mar 7]. http:/ / www.nhc.gov.cn/jkj/s3577/202001/ 6adc08b966594253b2b791be5c3b9467

7. Chinese Psychological Society. Preventing disease fighting disease, 2020 [in Chinese] [cited 2020 Apr 28]. http:/ / www.cpsbeijing.org/cms/show.action?code= publish_ff8080817000ff3001706647285d02f0\&siteid=100000\&chan nelid $=0000000188$

8. Ministry of Education. MoE requests psychological support be provided to relieve novel coronavirus-related stress, January 28, 2020 [in Chinese] [cited 2020 Apr 28]. http://www.moe.gov.cn/jyb_xwfb/gzdt_gzdt/ s5987/202001/t20200128_416721.html

9. Qiu J, Shen B, Zhao M, Wang Z, Xie B, Xu Y. A nationwide survey of psychological distress among Chinese people in the COVID-19 epidemic: implications and policy recommendations. Gen Psychiatr. 2020;33:e100213. https://doi.org/10.1136/gpsych-2020-100213

10. Gao J, Zheng P, Jia Y, Chen H, Mao Y, Chen S, et al. Mental health problems and social media exposure during COVID-19 outbreak. PLoS One. 2020;15:e0231924. https://doi.org/10.1371/journal.pone.0231924

Address for correspondence: Adriana Miu, Department of Psychiatry, University of Texas Southwestern Medical Center, 6363 Forest Park Rd, Dallas, TX 75235, USA; email: adriana.miu@utsouthwestern.edu

\section{Antibody Responses to SARS-CoV-2 at 8 Weeks Postinfection in Asymptomatic Patients}

\author{
Pyoeng Gyun Choe, ${ }^{1}$ Chang Kyung Kang, ${ }^{1}$ \\ Hyeon Jeong Suh, Jongtak Jung, EunKyo Kang, \\ Sun Young Lee, Kyoung-Ho Song, Hong Bin Kim, \\ Nam Joong Kim, Wan Beom Park, Eu Suk Kim, \\ and Myoung-don Oh
}

Author affiliations: Seoul National University Hospital, Seoul, South Korea (P.G. Choe, C.K. Kang, H.J. Suh, E.K. Kang, S.Y. Lee, N.J. Kim, W.B. Park, M.-D. Oh); Seoul National University Bundang Hospital, Seongnam, South Korea (J. Jung, K.-H. Song, H.B. Kim, E.S. Kim)

DOI: https://doi.org/10.3201/eid2610.202211

We compared levels of severe acute respiratory syndrome coronavirus 2 neutralizing antibodies in recovery plasma from 7 completely asymptomatic coronavirus disease patients with those in symptomatic patients in South Korea. We found that serologic diagnostic testing was positive for $71 \%(5 / 7)$ of completely asymptomatic patients, but neutralizing antibody response occurred in all 7 patients.

${ }^{1}$ These first authors equally contributed to this article. 